\title{
LA EJECUCIÓN FORZOSA DEL ACTO ADMINISTRATIVO EN EL DERECHO ESPAÑOL ${ }^{1}$
}

\section{THE ADMINISTRATIVE ACTS ENFORCEMENT IN THE SPANISH LAW}

\section{Antonio José SÁNCHEZ SÁEZ²}

SUMARIO: I. Introducción. II. El procedimiento de la ejecución forzosa de los actos administrativos. III. Los medios de ejecución forzosa. III. Principios generales de utilización de los medios de ejecución forzosa. IV. La ejecución forzosa y el derecho a la inviolabilidad del domicilio. V. Bibliografía.

RESUMEN: En este artículo se resume el régimen jurídico de la ejecución de los actos administrativos en el derecho administrativo español, cuya regulación se encuentra en la Ley 30/1992, de Régimen Jurídico de las Administraciones Públicas y del Procedimiento Administrativo Común. El acto administrativo es un acto de voluntad, deseo, conocimiento o juicio, emanado de una administración, que tiene el privilegio de la ejecutividad (es de obligado cumplimiento para sus destinatarios) y de la ejecutoriedad (en caso de renuencia por parte de los destinatarios, la propia Administración, sin recurso de terceros o de tribunales, puede hacerlos cumplir de manera coercitiva). En el derecho administrativo español los medios de ejecución forzosa son limitados a cuatro: apremio sobre el patrimonio, ejecución subsidiaria, multa coercitiva y compulsión sobre las personas. Para cada tipo de acto administrativo, dependiendo de su objeto, la regulación propende al empleo de un tipo de ejecución forzosa concreto. Por ejemplo, las deudas dinerarias suelen ser ejecutadas mediante el apremio sobre el patrimonio; las obligaciones de hacer, pueden ser ejecutadas mediante la ejecución subsidiaria o las multas coercitivas; las obligaciones personalísimas casi siempre exigen de una compulsión sobre las personas, etcétera. Sin embargo, cuando varios medios pueden ser posibles para hacer cumplir el mismo acto, la administración preferirá el empleo del medio menos lesivo de la libertad y patrimonio del administrado, en una clara aplicación del derecho fundamental a la libertad y a la propiedad.

Finalmente, se hacen algunas consideraciones sobre la ejecución de actos administrativos que pueden conllevar la entrada en el domicilio del administrado, y el juego en esos casos del que en España es el derecho fundamental a la inviolabilidad del domicilio.

Palabras clave: derecho administrativo español, acto administrativo, ejecución de actos administrativos, procedimiento administrativo, inviolabilidad del domicilio.

\footnotetext{
${ }^{1}$ Artículo recibido el 19 de febrero de 2015 y aceptado para su publicación el 11 de agosto de 2015.

${ }^{2}$ Profesor titular de derecho administrativo en la Facultad de Derecho en la Universidad de Sevilla.
} 
ABSTRACT. This paper describes the legal framework for the enforcement of Administrative acts in the Spanish administrative Law, which is in Act 30/1992, on the Legal Regime of Public Administrations and of the Common Administrative Procedure. Administrative act is an act of will, desire, knowledge or judgment issued by an Administrative body, who has the privilege of enforceability (it is mandatory for its recipients) and enforcement (in case of reluctance on the recipients, the Administration, without recourse to third parties or Courts can enforce coercively).

In the Spanish Administrative Law enforcement media are limited to four: constraint on capital, subsidiary execution, coercive penalties, and compulsion on people. For each type of administrative media, depending on its purpose, regulation tends to the use of a particular type of enforcement. For example, money claims are usually implemented through the constraint on capital; obligations to do, can be executed by the subsidiary execution or periodic coercive penalty payments; personal obligations almost always require a compulsion on people, etc. However, when various legal media may be possible to enforce the same act, the Administration prefers the use of the less harmful means, in a clear application of the fundamental right to liberty and property.

Finally, some considerations are made about the implementation of administrative measures that may involve the entry into the home of recipients, and the game in those cases of the fundamental right to the inviolability of the home.

Keywords: Spanish Administrative Law, Administrative Act, Administrative Acts Enforceability, Administrative Procedure, Inviolability of the Home.

\section{INTRODUCCIÓN}

La crisis económica que viene azotando a Europa, y a España en particular, está provocando crecientes dificultades en las administraciones españolas (estatal, autonómicas y locales) para ejecutar sus actos administrativos. Ello ha puesto de primera línea de nuevo un tema clásico en la doctrina del derecho administrativo, que no por ello deja de tener relevancia en nuestros tiempos. Consideramos, por tanto, muy interesante que nuestros colegas juristas mexicanos puedan conocer, de manera resumida, su régimen jurídico en España. En nuestro país, la ejecución de los actos administrativos viene regulada, desde hace ya algunos años, en la Ley 30/1992, del 26 de noviembre, de Régimen Jurídico de las Administraciones Públicas y del Procedimiento Administrativo Común (LPAC, en adelante), varias veces modificada desde entonces, incluso recientemente.

Para empezar, podríamos decir que, a diferencia de lo que ocurre en las relaciones entre particulares, que deben someter sus conflictos a los tribunales (heterotutela), abandonada ya en las sociedades occidentales modernas la justicia del "ojo por ojo", 
la administración es guardiana de los intereses generales frente a los particulares, y los protege por sí misma. La ejecución forzosa de los actos administrativos es consecuencia del privilegio de autotutela de la administración, uno de los fundamentos del derecho administrativo como derecho tutor de los intereses generales, que atribuye a los actos administrativos dos atributos:

Ejecutividad: los actos administrativos son de cumplimiento obligatorio desde el momento en que son eficaces (desde su dictado o notificación, generalmente, según los casos: artículos 56 y ss., LPAC), siendo indiferente para la administración a la hora de dictarlos la voluntad del administrado de cumplirlos o no; como excepción, no serán ejecutivos los actos en los que haya recaído suspensión administrativa o judicial o las sanciones que no pongan fin a la vía administrativa (artículo 138.3, LPAC)

Ejecutoriedad: si el administrado se negara a cumplir el contenido del acto, la administración, por sí misma, sin necesidad de acudir a los tribunales, puede obligarlo a hacerlo a través de alguno de los medios recogidos en el capítulo $V$, título VI, de la LPAC, con la forma, requisitos y consecuencias que veremos a continuación (artículos 94 y ss.). Es aquí donde insertamos el tema objeto de estudio en esta investigación.

La ejecución forzosa de los actos administrativos es una forma legítima de coacción administrativa, a diferencia de la vía de hecho, que es una actuación nula de pleno derecho (artículo 62.1, inciso e, LPAC). También puede la administración emplear la coacción directa cuando tiene necesidad de hacer cumplir mandatos públicos con ocasión de calamidades públicas o razones perentorias de interés público (por ejemplo, artículo 26 de la Ley 14/1986, del 25 de abril, General de Sanidad, artículo 56 del Real Decreto Legislativo 1/2001, del 20 de julio, por el que se aprueba el texto refundido de la Ley de Aguas, artículo 21.1,j) LRBRL, artículo 120 LEF y otros casos recogidos en la Ley Orgánica 10./1992, del 21 de febrero, sobre Protección de la Seguridad Ciudadana y en la Ley Orgánica 4/1981, del 10. de junio, de los Estados de Alarma, Excepción y Sitio).

Las administraciones, en puridad, sólo pueden ejecutar actos administrativos dirigidos a personas físicas o jurídicas sometidas al derecho privado, pero no a otras administraciones (a las que, como máximo, podrán sustituir en el ejercicio de una competencia no ejercitada, por ejemplo, las comunidades autónomas en relación con los entes locales, siendo necesaria la intervención de los tribunales de la jurisdicción contencioso-administrativa en caso de discrepancia) 


\section{EL PROCEDIMIENTO DE LA EJECUCIÓN FORZOSA DE LOS ACTOS ADMINISTRATIVOS}

\section{El apercibimiento previo (artículo $95 \angle R J A P$ y PAC)}

El acto administrativo es un título ejecutivo en sí mismo, como pueden ser los contratos o las leyes y reglamentos que puedan ser de directa aplicación.

Conforme al artículo 95, LPAC, es necesario que exista un acto administrativo para que pueda ser ejecutado, y para hacerlo será imprescindible también que la misma administración que lo dictó aperciba al particular que se ha negado a cumplirlo de que si persiste en su actitud y no cumple en un plazo prudentemente indicado, iniciará el procedimiento de ejecución forzosa del acto administrativo.

\section{Creación del título ejecutivo}

El acto administrativo, normalmente de gravamen, es un título ejecutivo que la administración quiere que el particular cumpla, como se ha dicho. Tenemos que distinguir, por tanto, entre tres actos administrativos consecutivos: el que se notificó en primer lugar, y cuyo contenido el administrado debe cumplir, normalmente una resolución administrativa; el acto de apercibimiento, acto administrativo de trámite que le otorga al particular un plazo para que cumpla lo mandado; $y$, en tercer lugar, en caso de que no se cumpla la condición anterior, el acto administrativo de trámite que inicia el procedimiento administrativo de ejecución forzosa del acto originario. ${ }^{3}$

La ejecución forzosa no requiere la firmeza del acto, de tal forma que aunque el administrado interpusiera un recurso de reposición o de alzada, la administración podría proceder a la ejecución. Para evitarlo, los administrados recurrentes suelen solicitar la suspensión de la ejecutividad del acto, más viable desde que la Ley 4/1999, del 13 de enero, de Modificación de la LPAC, añadió el artículo 111.3: “La ejecución del acto impugnado se entenderá suspendida si transcurridos treinta días desde que la solicitud de suspensión haya tenido entrada en el registro del órgano competente para decidir sobre la misma, éste no ha dictado resolución expresa al respecto".

\section{Elección del medio de ejecución aplicable}

A veces es posible el uso de varios medios de ejecución forzosa, en cuyo caso el artículo 96.2 previene que deberá escogerse "el menos restrictivo de la libertad individual". En caso de que no hubiera una evidente pérdida de esa libertad, el

\footnotetext{
${ }^{3}$ El acto administrativo de gravamen cuyo cumplimiento se persigue debe ser dictado y notificado al particular; en caso contrario, la ejecución del mismo sería definible como vía de hecho (artículo 93, LPAC).
} 
principio de proporcionalidad (artículo 96.1, LPAC) será el que debe orientar esa elección, salvo que sea la propia norma la que predetermine el medio a emplear, claro está. La multa coercitiva y la ejecución subsidiaria suelen ser tenidos por la doctrina como los medios menos lesivos o dañosos. Esos principios deben intentar reducir el ineludible margen de discrecionalidad que la administración dispone a la hora de elegir el medio más adecuado. También puede contribuir a hacerlo una ley sectorial que permita $-\mathrm{y}$, en cierta manera, incentive- el uso de multas coercitivas o la compulsión. ${ }^{4}$

En los casos en que sólo proceda un medio o la propia LPAC excluya el uso de otro u otros la elección estará clara, y el empleo de otro medio podría ser nulo por prescindir del procedimiento legalmente establecido. ${ }^{5}$

\section{LOS MEDIOS DE EJECUCIÓN FORZOSA}

Son cuatro y sólo cuatro (numerus clausus), de forma que el empleo de alguno que no esté entre los recogidos en el artículo 96, LPAC daría lugar a su nulidad. Son el apremio sobre el patrimonio, la ejecución subsidiaria, la multa coercitiva y la compulsión sobre las personas.

\section{Apremio sobre el patrimonio}

Recogido en el artículo 97, LPAC, el apremio es el medio adecuado para el cobro de deudas líquidas adquiridas por los administrados frente a la administración. El pago de una deuda es, en esencial, un acto no personalísimo de hacer, por lo que, en teoría, nada impide el uso de la ejecución subsidiaria, en caso de que el administrado resultara insolvente, aunque no es lo corriente (en contra de esta opinión, González Pérez y González Navarro). El apremio es el medio de ejecución más concreto de los cuatro, por ser el que se plantea en un supuesto de hecho más especializado y por tener un procedimiento ad hoc recogido en las normas reguladoras del procedimiento recaudatorio en vía ejecutiva.

\section{A. Actos sobre los que procede}

\footnotetext{
${ }^{4}$ González Pérez y González Navarro consideran que no es la multa coercitiva la menos lesiva, pues crea una nueva obligación que no existe; por ejemplo, en la ejecución subsidiaria. En nuestra opinión todo depende del caso: si el administrado le da mucha importancia al hecho de ejecutar el acto por sí mismo o no y, en ambos casos, las consecuencias económicas que de ello deriven para su bolsillo.

${ }^{5}$ En este sentido, la STS del 14 de mayo de 1997 (RJ 1997\4368) declara nulas las multas coercitivas impuestas por una administración a un particular para obligarle a demoler unas obras de derivación y toma de agua, en ausencia de ley que las permitiera, siendo procedente la ejecución subsidiaria.
} 
La vía de apremio es utilizable cuando el obligado hubiera de satisfacer una cantidad líquida, determinada o determinable.

Se ha señalado agudamente que los restantes medios de ejecución forzosa pueden reconvertirse finalmente en la vía de apremio, ya que la ejecución subsidiaria se traduce en una deuda líquida que se gira al administrado obligado; las multas coercitivas, en caso de no pagarse, se pueden ejecutar igualmente por el apremio, y la compulsión puede traer como consecuencia la obligación de indemnizar por los daños y perjuicios ocasionados, lo que se acaba convirtiendo en cantidades líquidas a pagar (Sanz Larruga).

\section{B. Sujetos}

El apremio puede ser utilizado no sólo por una administración territorial o por administraciones instrumentales de personalidad pública (artículo 54 Ley 6/1997, de 14 de abril, de Organización y Funcionamiento de la Administración General del Estado, LOFAGE, en adelante), sino también por personas físicas o jurídicas de derecho privado (agentes de la administración pública, como los concesionarios de servicios públicos locales, artículo 128.4, 20. Reglamento de Servicios, o los beneficiarios de la expropiación, artículo 58.1 Reglamento de Expropiación Forzosa) y por administraciones de base privada, como las corporaciones 0 entes instrumentales de personalidad jurídica privada, siempre que exista una previa autorización legal para ello. Hay que distinguir, por tanto, al sujeto administrativo acreedor del crédito, que suele ser el titular de la potestad administrativa de apremio, del sujeto beneficiario de la misma, que puede ser o no ese mismo sujeto.

Por el contrario, el sujeto pasivo, que habrá de soportar el procedimiento, es el deudor del crédito frente a la administración, y sus sucesores en vida o mortis causa (artículos 41y 42 de la Ley 58/2013, del 17 de diciembre, en adelante LGT).

\section{Normativa}

El artículo 97 y la DA 5a. LPAC remiten su regulación a la legislación tributaria, es decir: la Ley 58/2003, del 17 de diciembre, General Tributaria (artículos 163-173), y el Real Decreto 939/2005, de 29 de julio, por el que se aprueba el Reglamento General de Recaudación (artículos 70-116), que entró en vigor el 10. de enero de 2006, este último en sustitución del Reglamento General de Recaudación aprobado por Real Decreto 1684/1990, del 20 de diciembre.

La STS (Sentencia del Tribunal Supremo) del 16 de abril de 1997 (RJ 1997\3143) distinguía tres periodos temporales a los que les eran aplicables tres normas distintas: 
la primera, desde la Ley 230/1963, del 28 de diciembre, General Tributaria; la segunda, desde la modificación sufrida en ésta por la Ley de Presupuestos del Estado para 1988, que creó el recargo de apremio y los intereses de demora; y la tercera, a partir de la Ley 25/1995, que recogió un recargo del 10\% desde el inicio del periodo ejecutivo y un recargo de apremio del $20 \%$ desde el dictado de la providencia de apremio. Habría que añadir una cuarta época, inaugurada por la LGT de 2003.

\section{Procedimiento a seguir}

Se trata de un procedimiento exclusivamente administrativo, cuyo inicio y tramitación compete sólo a la administración tributaria.

Requisito previo. Para empezar, es necesario, como siempre que haya que emplear un medio de ejecución forzosa, la existencia de acto declarativo previo debidamente notificado al particular (véase SSTS del 10 de noviembre de 1986 (RJ 1986/6181), 18 de mayo de 2002 (RJ 2002\4845) y 10 de diciembre de 2002 (RJ 2003\491).

Inicio e impulso del procedimiento de oficio. La LGT dispone (artículo 163.3) que el procedimiento de apremio se inicia e impulsa de oficio en todos sus trámites, y que una vez iniciado, sólo se suspenderá de acuerdo con la normativa tributaria.

Acto de iniciación. El procedimiento se inicia mediante la providencia de apremio (artículo 167, LGT), que es el acto administrativo de trámite que se debe notificar al deudor una vez que se constata la falta de pago en periodo voluntario (certificación de descubierto). Es un título ejecutivo contra el patrimonio del administrado que tiene la misma fuerza que una sentencia judicial

Efectos de la iniciación. Conforme a los artículos 167 y 168, LGT, produce tres efectos:

- Devengo del recargo del período ejecutivo, que puede ser del 5\%, $10 \%$ o $20 \%$ de la deuda (artículo 28, LGT);

- Comienzan a devengarse los intereses de demora (artículo 26, LGT), y

- Si no se efectuara el pago indicado por la providencia de apremio antes de los días indicados en el artículo 62.5, LGT (día 20 del mes en curso o día 5 del mes siguiente, según el día de notificación), procederá el embargo y enajenación de los bienes y derechos del administrado deudor.

Eventual impugnación de la providencia de apremio. El artículo 138 de la anterior LGT, de 1963 reformada, incluía los mismos motivos que el actual artículo 167.3 de la 
LGT de 2003, salvo el descrito en la letra e): "error u omisión en el contenido de la providencia de apremio que impida la identificación del deudor o de la deuda apremiada", si bien ya había sido señalado por la jurisprudencia (por ejemplo, STS del 20 de octubre de 1997 (RJ 1997\7145). ${ }^{6}$

\section{E. Desarrollo del procedimiento}

Suspensión. El procedimiento de apremio se suspenderá conforme a la regulación que se hace de los recursos y reclamaciones económico-administrativas; esto es, el artículo 235 de la propia LGT (que permite la suspensión si se garantiza el importe de la deuda, los intereses de demora que genere la suspensión y los recargos que pudieran proceder) si bien el artículo 135.2, RGR, dice que se suspenderá inmediatamente el procedimiento de apremio, sin necesidad de prestar garantía, cuando el interesado demuestre que se ha producido en su perjuicio error material, aritmético o de hecho en la determinación de la deuda, o bien que dicha deuda ha sido ingresada, condonada, compensada, aplazada o suspendida.

Embargo de bienes (artículo 169, LGT). Se embargarán bienes o dinero por el importe suficiente para cubrir la deuda no ingresada, los intereses devengados o que se hayan de devengar hasta la fecha del ingreso, los recargos en periodo ejecutivo y las costas del procedimiento. Los bienes a embargar deben ser los de mayor facilidad de venta y que le supongan una menor onerosidad al deudor, teniendo en cuenta la preferencia establecida en el artículo 169.2:

— Dinero efectivo o en cuentas abiertas en entidades de crédito.

— Créditos, efectos, valores y derechos realizables en el acto o a corto plazo.

- Sueldos, salarios y pensiones.

- Bienes inmuebles.

- Intereses, rentas y frutos de toda especie.

— Establecimientos mercantiles o industriales.

— Metales preciosos, piedras finas, joyería, orfebrería y antigüedades.

- Bienes muebles y semovientes.

— Créditos, efectos, valores y derechos realizables a largo plazo.

\footnotetext{
${ }^{6}$ No cabe alegar motivo distinto a los enunciados en la Ley (STS del 27 de marzo de 1997 [RJ 1997\2064]).
} 
- Se evitará también en lo posible la venta de los de valor notoriamente superior al de los débitos (artículo 101, RGR).

Contra la diligencia de embargo sólo se podrán oponer los motivos tasados del artículo 170.3, entre los cuales la suspensión del procedimiento de apremio suele ser el más usual.

Depósito de los bienes embargados: los artículos 94-96 del nuevo RGR establecen los lugares donde han de quedar depositados los bienes embargados hasta la enajenación de los mismos: las cuentas bancarias quedarán en poder de los bancos, mientras que para los bienes muebles se preferirá su depósito en instalaciones administrativas o en empresas del ramo. Sólo en casos de difícil movilidad quedarían los bienes embargados en posesión del deudor.

Adjudicación de los mismos. La enajenación de los bienes o derechos embargados sólo procederá después de realizadas las actuaciones previas previstas en los artículos 97, 98 y 99 del RGR: tasación contradictoria, obtención de los títulos de propiedad de los bienes embargados en los casos en que así procediese y formación de lotes.

La enajenación en sí se podrá realizar una vez expedido acuerdo de enajenación, por subasta (en la mayoría de los casos), concurso (cuando la subasta del bien pudiera desestabilizar el mercado) o adjudicación directa (para casos, sobre todo, de bienes perecederos), de forma que se devuelva al embargado la parte sobrante obtenida tras la resta de los conceptos debidos. Procederá la adjudicación del bien a la Hacienda Pública si se trata de un bien que pudiera interesarle y sólo cuando no se hubieran adjudicado los bienes en el procedimiento de enajenación (artículo 172.2, LGT). Caben ahora también las subastas telemáticas y la participación de los interesados en las mismas.

Terminación del procedimiento. Mediante resolución administrativa, que verifique alguno de los tres supuestos recogidos en el artículo 173, LGT. El pago (artículo 173.a) puede realizarse directamente a la Administración o a una entidad colaboradora (una entidad bancaria, por ejemplo, en cuyo caso, la demora o pérdida del mismo dará lugar a responsabilidad de la misma, no del administrado deudor (véase STS del 16 de abril de 1997 (RJ 1997\3143). ${ }^{7}$

\footnotetext{
${ }^{7}$ Si el crédito se declarara incobrable, por falta de liquidez o de patrimonio del administrado, podrá reanudarse el procedimiento de apremio antes del plazo de prescripción cuando la administración tuviera constancia de la solvencia sobrevenida del obligado al pago. Tras la terminación del
} 
La prescripción de la deuda termina el procedimiento. También cabe la compensación de la deuda con otra que la administración tuviera con el administrado-deudor, conforme a lo establecido en el artículo 68, RGR. La condonación sólo sería posible previa ley (artículo 75, RGR). Además, cualquiera de estos supuestos dará lugar a la suspensión automática del procedimiento de apremio, como se ha dicho antes.

\section{Ejecución subsidiaria}

Como su nombre indica, se trata de un medio de ejecución forzosa que permite a la Administración ejecutar por sí misma (directa o indirectamente) el contenido del acto al que estaba obligado el administrado renuente a su cumplimiento, a su costa (artículo 98, LPAC). Lo esencial de este medio de ejecución forzosa es que no impone ninguna carga nueva al administrado que no estuviera determinada en el acto administrativo, por lo que suele ser considerado como el medio más proporcionado. ${ }^{8}$

Existen multitud de casos en los que una Administración se subroga o sustituye la actuación de otra Administración o tercero renuentes: desde el artículo 155, CE o el artículo 67, LRBRL, hasta otros ejemplos de la legislación sectorial, como la expropiación-sanción en materia urbanística, la sustitución de un sistema de ejecución del planeamiento privado por uno público en caso de incumplimiento de los deberes por parte de los propietarios, la sustitución de la Administración local por la autonómica en temas de lucha contra el ruido, etcétera.

\section{A. Actos sobre los que procede}

Procede para ejecutar actos no personalísimos de hacer; es decir, actos que pueda realizar cualquier persona distinta de la obligada a ello, sin menoscabo de los intereses públicos en juego derivados del cumplimiento del acto administrativo. Si, por ejemplo, el pintor Antonio López incumpliera el encargo personal de retratar a la

procedimiento, el adjudicatario del bien enajenado podrá solicitar expresamente en el acto de la adjudicación el otorgamiento de escritura pública de venta del inmueble y se devuelve, como hemos dicho arriba, la parte sobrante al deudor, quedando levantado el embargo.

${ }^{8}$ Cabe, de todas formas, preguntarse si también es el medio menos restrictivo de la libertad individual, cuestión ésta diversa y no siempre clara, porque es precisamente esa libertad la que queda coartada cuando es la administración la que contrata a un tercero el cumplimiento del acto, que no ha elegido el administrado, con un presupuesto final y unas características que se le imponen (a favor de esta interpretación de la ejecución subsidiaria como restrictiva de la libertad personal, véase la STS del 26 de octubre de 1988, artículo 8.231; en contra, Rebollo Puig, considerando la multa coercitiva mucho más gravosa). 
familia real, resulta evidente que no cabría una ejecución subsidiaria. Más difícil de precisar es el contenido personalísimo de un proyecto técnico de contenido no artístico.

\section{B. Requisitos}

Carece de un régimen detallado, de forma que ha sido la jurisprudencia y la doctrina la que han ido induciendo principios y reglas básicas. En cuanto a la regulación, basta con la autorización genérica contenida en la LPAC. De forma que su empleo no requiere, al contrario que las multas coercitivas o la compulsión personal, de una previa habilitación legal, teniendo en cuenta, como hemos dicho, que este medio de ejecución resulta inocuo en el sentido de que no añade ninguna carga nueva no necesaria al administrado incumplidor que éste no tuviera desde el momento en el que se le notifica el acto administrativo. ${ }^{9}$

Sí que es necesario, como siempre, la notificación del acto administrativo, la identificación de la situación de incumplimiento, apercibimiento previo y atribución de un nuevo plazo al obligado (que, en casos de urgencia, pueden reducirse adecuadamente, si bien -entendemos - no hasta el extremo de suponer una inmediatez tal que le impidieran de facto o de iure contratar a la empresa que haya de cumplir el contenido del acto), y la notificación del acto de inicio del procedimiento ejecutivo de ejecución subsidiaria. ${ }^{10}$

También, suele ser normal que la Administración contrate a un tercero mediante el contrato de arrendamiento de servicios, con un pliego de condiciones que recoja las mismas obligaciones a las que estaba llamado el administrado originario; la otra opción, menos plausible por lo que tiene de secuestro del mercado, es la de la propia ejecución de la obligación por los medios propios de la Administración, opción que

\footnotetext{
${ }^{9}$ Hemos de pensar, no obstante, que el empleo de este medio de ejecución forzosa puede acarrear el empleo de otros para conseguir la finalidad que perseguía el acto administrativo: puede ocurrir, en efecto, en primer lugar, que el administrado se negara a la ejecución subsidiaria, en cuyo caso cabría emplear multas coercitivas si la Ley lo permitiera, o incluso la compulsión sobre su persona, para que tolerara la ejecución a realizar por persona interpuesta. En segundo lugar, podría suceder que, una vez ejecutado el acto, el particular rehusara pagar la factura de los costes que la administración o su contratista le pasaron: en este caso cabría emplear el apremio sobre su patrimonio.

${ }^{10}$ En la STS del 22 de abril de 2002 (RJ 2002\4404), el Ayuntamiento de Bailén procede a la clausura de una nave industrial dedicada a la fabricación de hormigón, que incumplía el RAMINP (Reglamento de Actividades Molestas, insalubres, nocivas y peligrosas). Pero, antes de ejecutar subsidiariamente el cierre de dicha empresa, procedió a tramitar un procedimiento administrativo de clausura, con audiencia previa del propietario.
} 
habría que someter a las posibilidades y presupuestos de hecho que indica el texto refundido de la Ley de Contratos del Sector Público, y particularmente que no hubiera habido ofertas de empresarios para la ejecución de obras en licitación previamente efectuada (preferencia de la ejecución por terceros a la ejecución por la Administración, ya se trate de una ejecución directa por ella misma o a través de otros medios públicos de administraciones instrumentales 0 de otras administraciones, previa encomienda de gestión). ${ }^{11}$

\section{Determinación del importe de los gastos que acarree el empleo}

de este medio de ejecución

El importe de los gastos debe ser razonable y proporcionado a la actuación realizada: normalmente la Administración saca a subasta o concurso las obras a las que estaba obligado el administrado originario, lo que le da un sentido más o menos objetivo al presupuesto por el que la administración contrata al ejecutor subsidiario. A pesar de ello, resulta evidente que si el particular hubiera realizado él a su costa desde un principio aquello a lo que estaba obligado podría haber optado entre hacerlo él mismo (con el subsiguiente ahorro, como ocurre a menudo cuando se trata, por ejemplo, de unas obras en el inmueble ocupado por una comunidad de propietarios en la que uno de los vecinos se dedica al ramo) o contratar a alguna empresa conocida que le hubiera merecido más confianza -y quizá también hubiera resultado más económica- que aquella otra que hubiera resultado designada por la Administración, de darse el caso.

Un límite evidente a los gastos que tiene que pagar el administrado resulta de la necesidad de que lo realizado por el ejecutor subsidiario nunca puede exceder de la obligación que pesaba sobre el administrado (STS del 18 de abril de 1989, artículo 3.118), si bien a veces resulta imprescindible la ejecución de estudios técnicos de preparación o seguridad previos o de guardia y seguridad de lo realizado, cuyo coste se sumará legítimamente a la cuenta de los trabajos realizados por la empresa o Administración ejecutora.

Tanto el importe de la ejecución como cualquier otro acto de trámite del procedimiento de ejecución subsidiaria podrían ser impugnados autónomamente

\footnotetext{
${ }^{11}$ En caso de sucesión en vida o mortis causa en la situación pasiva del obligado, su causahabiente estará obligado en su lugar a ejecutar el acto administrativo originario, al tratarse de actos no personalísimos (artículo 31.8, LPAC).
} 
siempre que adolecieran de algún vicio jurídico independiente del acto administrativo que les da amparo (STS de 16 de mayo de 1977, artículo 3.724).

A los gastos habría que sumar el importe de los daños y perjuicios derivados del incumplimiento del acto administrativo originario por el administrado (artículo 98.3, LPAC). Todos los gastos se pueden liquidar provisionalmente antes de realizar la ejecución subsidiaria, si la administración entendiera que es necesaria para poder financiarla, a reserva de la liquidación definitiva (artículo 98.4). ${ }^{12}$

\section{Multa coercitiva}

Medio de ejecución forzosa de los actos administrativos recogido en el artículo 99 LPAC, conocido en la doctrina alemana como "dinero coactivo" (Zwangsgeld). Una definición clásica ha sido dada en la Sentencia del Tribunal Constitucional (STC) 239/1988, del 14 de diciembre. ${ }^{13}$

\section{A. Naturaleza jurídica}

\footnotetext{
${ }^{12}$ La liquidación provisional es cosa distinta al presupuesto inicial de gastos que la administración gira al administrado incumplidor junto con la providencia de apremio, para que ejecute el acto antes de iniciar la ejecución subsidiaria: vincula a la Administración en el sentido de que ese mismo presupuesto es el que la Administración debe licitar para contratar con una empresa tercera, en caso de negarse el administrado a ejecutar el acto. Las liquidaciones complementarias sólo son admisibles por imprevistos sobrevenidos.

${ }^{13}$ Fundamento jurídico 20.: “no se impone una obligación de pago con un fin represivo o retributivo por la realización de una conducta que se considere administrativamente ilícita, cuya adecuada previsión normativa desde las exigencias constitucionales del derecho a la legalidad en materia sancionadora pueda cuestionarse, sino que consiste en una medida de constreñimiento económico, adoptada previo el oportuno apercibimiento, reiterada en lapsos de tiempo y tendente a obtener la acomodación de un comportamiento obstativo del destinatario del acto a lo dispuesto en la decisión administrativa previa. No se inscriben, por tanto, estas multas en el ejercicio de la potestad administrativa sancionadora, sino en el de la autotutela ejecutiva de la Administración, previstas en nuestro ordenamiento jurídico con carácter general por el artículo 102 de la L. P. A. cuya constitucionalidad ha sido expresamente reconocida por este Tribunal —SSTC 22/1984, del 17 de febrero (RTC 1984\22); 137/1985, del 17 de octubre (RTC 1985\137), y 144/1987, del 23 de septiembre (RTC 1987\144)—, y respecto de la que no cabe predicar el doble fundamento de la legalidad sancionadora del artículo 25.1, CE a que se refiere la STC 101/1988, del 8 de junio (RTC 1988\101), esto es: de la libertad (regla general de la licitud de lo no prohibido) y de seguridad jurídica (saber a qué atenerse), ya que, como se ha dicho, no se castiga una conducta realizada porque sea antijurídica, sino que se constriñe a la realización de una prestación o al cumplimiento de una obligación concreta previamente fijada por el acto administrativo que se trata de ejecutar, y mediando la oportuna conminación o apercibimiento".
} 
Como queda claro de la lectura de la STC anterior, las multas coercitivas no son sanciones administrativas, sino medidas de constreñimiento económico no inscritas en el ámbito de la potestad sancionadora, sino en el principio de autotutela ejecutiva de las administraciones públicas. Es por eso por lo que el artículo 99.2, LPAC considera independientes y compatibles las multas coercitivas con las sanciones que puedan imponerse al administrado incumplidor. ${ }^{14}$

La finalidad de la multa coercitiva es doblegar la voluntad del administrado renuente a cumplir el acto administrativo, mediante la imposición de pago de cantidades dinerarias de cantidad moderada que, no obstante, por repetidas, pueden suponer un menoscabo económico en el particular lo suficientemente importante como para compelerle a cumplir. Carecen de una finalidad retributiva, aunque en esencia se imponen de forma sucesiva como consecuencia del incumplimiento del acto original. Es por ello por lo que García de Enterría las considera una figura intermedia entre la ejecución forzosa y la sanción (García de Enterría). Las sanciones tampoco tienen finalidad retributiva, sino disuasoria de la comisión de futuras infracciones.

\section{B. Actos sobre los que procede}

Conforme al artículo 99.1, LPAC, procede para ejecutar:

a. Actos personalísimos en los que no procede la compulsión directa: es decir, actos personalísimos de hacer. Por ejemplo, como ya se ha dicho arriba, la obligación de un artista contratado personalmente por una administración de realizarla él mismo, no un discípulo suyo o su escuela-taller.

b. Actos personalísimos en los que, procediendo la compulsión, la Administración no la estimara conveniente: se entiende que por tener un contenido poco relevante 0 se entienda que el empleo de la compulsión sería claramente desproporcionado. Nos remitimos aquí a lo que dijimos al comienzo de este comentario en relación con la elección, por parte de la Administración, del medio de ejecución forzosa más adecuado.

c. Actos cuya ejecución pueda el obligado encargar a otra persona: el mismo presupuesto de hecho de la ejecución subsidiaria; esto es, actos no personalísimos de hacer. No cabría frente a actos de no hacer o soportar, que, en esencia, son actos personalísimos frente a los que cabe compulsión (por ejemplo, permitir la

\footnotetext{
${ }^{14}$ Para profundizar en la distinción entre la multa coercitiva y la sanción administrativa la STS del 14 de mayo de 1997 (RJ 1997\4368) y la STSJ de Castilla y León del 18 de diciembre de 2000 (RJCA 2001\211).
} 
entrada en domicilio a una empresa municipal encargada de desratizar una calle concreta del pueblo). En el caso de esta letra c), se entiende que la administración, en caso de habilitación legal expresa previa, podría optar entre la ejecución subsidiaria o la multa coercitiva, o también usarlos sucesivamente, en primer lugar las multas coercitivas y luego la ejecución subsidiaria, si con ellas no se doblegó la voluntad incumplidora del particular.

\section{Requisitos}

Al suponer la imposición de una obligación nueva, se requiere que una ley sectorial expresamente las autorice, ley formal para González Pérez y González Navarro, aunque entendemos que también sería posible su autorización por medio de un real-decreto legislativo, al existir una previa delegación legislativa previa (es el caso del artículo 119 del RDL 1/2001, del 20 de julio, de Aguas). No vale bajo ningún caso el uso de un simple reglamento. Véase STSJ de Madrid del 28 de mayo de 2003 (RJCA 2003\683) y STSJ del País Vasco del 16 de septiembre de 2002 (JUR 2003\98596). ${ }^{15}$

Toda habilitación legal que permita el uso de multas coercitivas debe contener los siguientes elementos (González Pérez y González Navarro):

- Supuestos en los que procede;

— Quién puede imponerlas;

- Tiempo que ha de transcurrir para imponerlas, aunque este requisito apenas se da en la casuística legislativa sectorial existente hasta la fecha;

- Plazos o periodicidad;

- Cuantía máxima posible de la multa, y

- Condicionamientos a los que debe someterse la discrecionalidad de la Administración que ejerce esta potestad: normalmente se exige proporcionalidad de la multa con la obligación principal a cumplir por el administrado.

\footnotetext{
${ }^{15}$ Son muchos los sectores del derecho administrativo donde las leyes permiten su uso (artículo 33.2 de la Ley del 28 de julio de 1988, de Costas; artículo 26 de la Ley del 29 de julio de 1988, de Disciplina e Intervención de las Entidades de Crédito; artículo 39.4 de la Ley del 27 de marzo de 1989, de Conservación de los Espacios Naturales y de la Flora y Fauna Silvestres; Ley de Defensa de la Competencia; LO de Protección de la Seguridad Ciudadana, etcétera).
} 
- El apercibimiento previo es imprescindible, con indicación del plazo para cumplir la obligación. ${ }^{16}$

Otro requisito, éste más ambiguo que el anterior, es la razonabilidad de su empleo, es decir, la adecuabilidad en la elección de las multas coercitivas como medio de ejecución forzosa, reflexión ésta en la que se podría pecar tanto por exceso (en casos en que se elija como medio de ejecución frente a la ejecución subsidiaria) como por defecto (cuando se escoge frente a la compulsión sobre las personas). Tras la elección, se hace preciso cuantificar las multas conforme al principio de proporcionalidad, lo que implica cierta discrecionalidad, aunque limitada por el valor económico de aquello a lo que estaba obligado el administrado y por la horquilla económica que puede imponer la ley habilitante (véase STSJ de Galicia del 31 de julio de 2003 (JUR 2003\22203). Esa misma discrecionalidad existe en relación con la determinación de la periodicidad de las multas, que puede encontrar límites, igualmente, en la ley habilitante. Ambos extremos (cuantía y periodicidad) son enjuiciables por la jurisdicción contencioso-administrativa: así, la STS del 6 de abril de 1982 (artículo 2.387), anuló unas multas coercitivas impuestas diariamente, por entender el juez que no dejaban al administrado el tiempo suficiente como para cumplir con la obligación principal, obligación que debía ser compleja cuando para cumplirla se había dejado un plazo de dos meses. La STS del 10 de julio de 1984 (artículo 5.577) rebajó el importe de una multa coercitiva de 6.750,000 ptas. a 2.299,170 ptas., por desproporcionada.

\section{Compulsión sobre las personas}

Compeler quiere decir obligar a alguien a hacer algo. Es el medio de ejecución forzosa más lesivo de la libertad individual, porque consiste, en esencia, en que la administración, a través de las fuerzas de seguridad de las que dispone, obliga físicamente al administrado a soportar la realización del acto administrativo por la Administración o por un tercero. Viene recogida en el artículo 100, LPAC. Se trata, por tanto, de un medio de ejecución forzosa vicarial, que sólo se emplea en última instancia, cuando la Administración considera que el uso de multas coercitivas no resultaría fructífero o cuando, empleadas éstas, el administrado sigue negándose a soportar una actuación urgente.

\section{A. Actos sobre los que procede}

\footnotetext{
${ }^{16}$ Además, esta obligación debe estar también suficientemente delimitada (STS del 3 de diciembre de 1997 (artículo 8.828).
} 
Se usa para ejecutar actos administrativos que imponen una obligación personalísima de no hacer o soportar; es decir, una obligación que sólo el administrado destinatario del acto puede realizar. Pensemos, por ejemplo, en permitir la entrada al domicilio para que una empresa municipal la desratice o el deber sobrevenido de someterse a una cuarentena por riesgo de haber sido contagiado con el virus de la gripe aviar, tras un viaje a Camboya.

Si el acto a cumplir fuera personalísimo de hacer, no cabría la compulsión (nadie puede obligar físicamente a un pintor de reconocido prestigio, pongamos, Antonio López, a pintar una obra si, tras firmar un contrato, por cualquier circunstancia se negare a ello), ${ }^{17}$ sino el empleo de multas coercitivas, cuando una ley así lo permita. Si no hubiera ley que las permitiera o aun así tampoco se hubiera ejecutado la misma, la única posibilidad de ejecutar el acto es transformando la obligación personalísima de hacer en una deuda pecuniaria del obligado, consistente en los daños y perjuicios causados por el incumplimiento, y sería ejecutable por la vía del apremio sobre el patrimonio (artículo 100.2, LPAC).

\section{B. Requisitos}

Este medio de ejecución, al implicar el uso de la fuerza física por parte de la policía, como cualquier otra prestación personal compulsoria, exige una habilitación legal previa que expresamente lo autorice.

Debido a las especiales características de este medio de ejecución, tan proclives al abuso policial, el apartado 10. del artículo 100, in fine, exige el debido respeto a la dignidad de la persona y a los derechos que la Constitución reconoce. Se nos ocurre el caso de la clausura de una empresa en la que el empresario, para evitarlo, se ha encadenado dentro, y la policía, lejos de ejercer una violencia sobre las cosas, rompiendo las cadenas y sacando a la persona a peso, se sobrepasa ejerciendo la violencia física sobre el particular, siendo absolutamente innecesaria. En este caso la dignidad y la integridad física podrían haber sido dañadas. ${ }^{18}$

\footnotetext{
${ }^{17}$ Viene al caso el ejemplo, verídico, pues el pintor ha tardado 20 años en pintar a la familia real española, tras recibir el encargo por parte de Patrimonio Nacional de España. Ha sido entregado por fin en septiembre de 2014 el cuadro, que, por cierto, es magnífico, como no podía ser menos.

${ }^{18}$ Algunos derechos constitucionales pueden ser puestos en entredicho al emplear indebidamente la compulsión personal. Por ejemplo, si en el caso anterior el empresario, mientras es llevado en vilo por los agentes de policía tras haber sido desencadenado del interior de su local, comienza a gritar en contra de la actuación municipal de manera respetuosa y es acallado por los agentes, se estaría vulnerando su derecho fundamental a la libertad de expresión.
} 
Los casos en los que se obliga a una persona a mantenerse viva en contra de su voluntad o en contra de la voluntad de sus familiares, son especialmente sensibles, y pueden llegar a afectar a la dignidad humana, porque suele parecer, al menos subjetivamente, que la forma de vida en que permanecen les resulta indigna (cada uno puede imaginar algún caso conocido). ${ }^{19}$

El caso ocurrido en España de la alimentación forzosa del etarra De Juana Chaos, tras iniciar una huelga de hambre indefinida, al igual que otros tantos acaecidos con terroristas en los años ochenta, es bien conocido por la jurisprudencia en la medida en que se les obliga a soportar una alimentación de suero intravenosa. Son casos necesarios para proteger el derecho a la vida que no suponen un menoscabo a la integridad corporal, pero en los que se bordea constantemente la vulneración del derecho a la libertad y a la dignidad de la persona. EI TC ha tenido la ocasión de pronunciarse varias veces sobre el tema, dejando claro que no existe un derecho a la muerte o un derecho a la libertad que pueda suponer la muerte por encima de la obligación de las instituciones sanitarias de aplicar tratamientos de alimentación forzosa, considerando que ello no viola otros derechos, como el de libertad, el de seguridad o el de libertad ideológica. ${ }^{20}$

\section{El desahucio administrativo y e/interdictum proprium}

Se trata de una forma específica de compulsión sobre las personas, a través del cual se expulsa o lanza a una persona física o jurídica de bienes demaniales de una administración. La diferencia entre el desahucio administrativo y el llamado interdictum proprium (es decir, la recuperación de oficio, por la propia administración, de la posesión indebidamente perdida de uno de sus bienes) son tres:

- El desahucio implica que la persona física o jurídica que debe ser expulsada estuvo poseyendo el bien anteriormente con justo título, pero que dicho título, con

\footnotetext{
${ }^{19}$ En estos casos, el uso de la alimentación forzosa, el uso forzoso del respirador artificial no resulta en sí mismos indignos (salvo que se haga de una manera indignante); lo indigno (repito, a los ojos del paciente o de sus familiares) puede ser la situación en la que les pone el empleo de esos medios: vivir en unas condiciones penosas sin quererlo. No existe el derecho a la muerte, salvo que la persona exprese claramente su voluntad de no someterse al tratamiento que la mantiene con vida (desconectarla del respirador artificial, como ocurrió en Andalucía a principios de 2007 con la paciente doña Inmaculada Echevarría) o, en caso de estar inconsciente, si, como ocurre en la legislación de alguna comunidad autónoma, hubiera depositado su testamento vital contrario a estos tratamientos.

${ }^{20}$ La libertad no ampara el derecho a poder rechazar tratamientos médicos encaminados a proteger la vida de las personas (véase SSTC 67/1991, del 22 de marzo, 11/1991, del 17 de enero, 137/1990, del 19 de julio o 120/1990, del 27 de mayo).
} 
posterioridad, decayó, se extinguió o caducó, mientras que en el interdictum proprium la posesión directamente se ha usurpado por otro sujeto, careciendo de título alguno, precio o no, para ello.

- En segundo lugar, derivado de esa primera diferencia, podríamos decir que en el desahucio se trata de expulsar a alguien de un sitio en el que estaba morando, viviendo. Hay cierto sentido de permanencia en la posesión. Se trata de una potestad más específica que la propia de recuperar la posesión indebida de los bienes demaniales y patrimoniales, posesión que se puede estar realizando sin tener por qué estar morando o viviendo en ese bien.

- En tercer lugar, la normativa básica o de aplicación general del desahucio y del interdictum proprium sólo permite el primero para los bienes demaniales, mientras que el segundo también la permite en los patrimoniales (artículos 55-58). Para desahuciar administrativamente a alguien hace falta ejercitar el llamado interdictum proprium, que puede ser ejercitado en cualquier momento tras la usurpación en caso de bienes demaniales y en el plazo máximo de un año (plazo en el que debe iniciarse el procedimiento de recuperación posesoria), en caso de bienes patrimoniales. ${ }^{21}$

La regulación del desahucio, con carácter básico para todas las administraciones, se encuentra en los artículos 58-60 de la Ley 33/2003, del 3 de noviembre, de Patrimonio de las Administraciones Públicas. Dos requisitos de procedimiento se derivan de esa normativa:

- La tramitación de una previa declaración de extinción o caducidad del título con el que el administrado ocupaba el bien, procedimiento contradictorio en el que se dará audiencia al poseedor;

- La notificación de la orden de expulsión al administrado, caso de producirse, al que se le debe dar un plazo máximo de ocho días legales para salir del bien por su voluntad. En caso contrario, las fuerzas y cuerpos de seguridad procederían a ejecutar el lanzamiento mediante el empleo de la compulsión sobre la persona del administrado, pudiendo usar la administración imponer carácter previo, potestativamente, multas coercitivas de hasta $5 \%$ del valor de los bienes ocupados, reiteradas por periodos de ocho días, hasta que se produzca el desalojo. Los

\footnotetext{
${ }^{21}$ Por lo demás, el procedimiento, con algunos matices de forma, es esencialmente idéntico en ambos casos.
} 
gastos derivados del desalojo y los perjuicios causados por la tardanza se podrán cobrar a través de la vía de apremio.

Obsérvese que sólo se habla de bienes demaniales en la LPAP (lo mismo que ocurre, reiterando esa previsión, en las leyes autonómicas sobre patrimonio autonómico o local), y, por analogía, de los bienes patrimoniales que se vayan a destinar a obras o servicios públicos, pero otras normas permiten el desahucio de otros tipo de bienes: la normativa local, en particular el RBEL (artículos 120-135), permite el desahucio de los bienes comunales y de los bienes patrimoniales de las corporaciones locales con ocasión de la extinción de contratos de arrendamiento o de otros derechos personales constituidos a favor de su personal por razón de los servicios que presten; la LEF permite el desahucio de bienes adquiridos por las administraciones mediante expropiación (como procedimientos administrativos reconocidos implícitamente en los artículos 51 y 52, 60. de la LEF); la normativa autonómica suele permitir el empleo del desahucio para expulsar a los que usurpan viviendas de protección oficial sin justo título o con título caducado (por ejemplo, en el artículo 16 de la Ley 13/2005, del 11 noviembre, de medidas para la Vivienda Protegida y el Suelo de la CA de Andalucía) y para que el concesionario de un contrato de concesión de obra pública pueda recabar la instrucción del procedimiento de desahucio administrativo para hacer viable la construcción, modificación y explotación de la obra pública, así como la realización de cuantas acciones sean necesarias para hacer viables los derechos del concesionario. ${ }^{22}$

\section{PRINCIPIOS GENERALES DE UTILIZACIÓN DE LOS MEDIOS DE EJECUCIÓN FORZOSA}

Vistos ya los cuatro medios de ejecución forzosa admitidos, con base en el artículo 149.1, 18, por la regulación básica de procedimiento administrativo de las administraciones públicas, conviene ahora inducir los principios generales que coordinan y dan sentido a la ejecución forzosa de los actos administrativos. Esos principios son los siguientes:

\footnotetext{
${ }^{22}$ Como también hace la Ley 13/2003, del 23 mayo, del Estado, que regula ese mismo contrato administrativo típico. Otros casos singulares son los de la Ley riojana 5/2005, del 25 de octubre, que permite al consorcio de Aguas y Residuos de La Rioja usar la potestad de desahucio para recuperar la posesión perdida de sus bienes. Véase SSTSJ de Madrid del 19 de septiembre de 2002 (RJCA 2002133743), de Cantabria del 24 de octubre de 2000 (RJCA 200012511), de Andalucía del 31 de mayo de 2001 (RJCA 20011304294), de Extremadura del 19 de septiembre de 2002 (RJCA 2002\1250) y del País Vasco del 4 de marzo de 2003 (RJCA 2003।703).
} 
Respeto debido a la dignidad de la persona y los derechos fundamentales (artículo 100, LPAC), asignado específicamente a la compulsión, pero que bien puede predicarse de los demás medios de ejecución;

Principio de legalidad, para las multas coercitivas y la compulsión sobre las personas, en un sentido de vinculación positiva a la ley, si bien de aplicación general a los demás medios en cuanto a su vinculación negativa;

Principio de la menor onerosidad del medio a elegir (artículo 96.2, LPAC), de aplicación general;

Principio de proporcionalidad (artículo 96.2, LPAC), de aplicación general. No cabría, con base en este principio, realizar una ejecución subsidiaria injustificadamente más cara que la que se exigía al administrado originario; tampoco cabría imponer multas coercitivas muy elevadas o con plazos muy breves; ni tampoco embargar la vivienda habitual para el cobro de una sanción cuando antes se podría haber procedido contra el automóvil u otros bienes muebles, etcétera.

Principio de congruencia, que llama a la máxima reducción de la discrecionalidad administrativa en la elección del medio de ejecución a usar en cada caso, bien porque los presupuestos de hecho determinen una única opción posible, bien porque las leyes sectoriales no permitan el empleo de un medio concreto, bien por el juego conjunto de los demás principios aquí enunciados;

Nunca cabe imponer dos o más medios de ejecución forzosa a la vez: todo lo más, consecutivamente;

Principio formalista: Ios cuatro medios exigen la tramitación de un procedimiento administrativo propio, más o menos trazado en la LPAC según los casos. En caso contrario estaríamos hablando de una coacción ilegítima e incurriendo en vía de hecho.

Si para ejecutar un acto administrativo se precisa previamente entrar en el domicilio de una persona física o jurídica, se precisa autorización judicial o consentimiento del particular, lo que desarrollaremos a continuación. Véase STSJ de Castilla y León del 8 de octubre de 2001 (JUR 2001\294120).

Se prohíbe interponer interdictos (civiles o administrativos) contra la ejecución forzosa de actos administrativos en los que se cumpla el procedimiento establecido, y siempre que el órgano encargado de tramitarlo sea competente (artículo 101, LPAC). 


\section{LA EJECUCIÓN FORZOSA Y EL DERECHO A LA INVIOLABILIDAD DEL DOMICILIO}

Desde 1978 el artículo 18.2, Constitución Española (CE) exigía previa autorización judicial o concurrencia de flagrante delito para que se pudiera admitir la entrada en domicilio en contra del consentimiento de su titular, ya fuera persona física o jurídica (como veremos luego), y ello debido a que la intimidad personal y familiar se considera un derecho fundamental de la persona (artículo 18.1, CE). Más tarde, el artículo 87.2 de la LO 6/1985, del 10. de julio, del Poder Judicial, atribuyó a los jueces de Instrucción de la jurisdicción penal esa competencia, en concreto, “la autorización en resolución motivada para la entrada en domicilio y en los restantes edificios o lugares de acceso dependientes del consentimiento de su titular, cuando ello procediese para la ejecución forzosa de los actos administrativos". ${ }^{23}$

El concepto constitucional de domicilio del artículo 18.2, CE es más amplio que el concepto jurídico civil o administrativo. Así lo han constatado las SSTC 22/1984, del 17 de febrero, y 160/1991, del 18 de julio, conclusión que se extrae de la ya mencionada conexión que el TC hace de la inviolabilidad del domicilio y el derecho a la intimidad personal y familiar: de esto se colige que no todos los domicilios estarán igualmente protegidos frente a injerencias externas de la administración pública, o, a contrario sensu, que allí donde la entrada de la administración en un domicilio pudiera poner en riesgo o peligro dicha intimidad, será necesaria, más allá de una posible habilitación en la legislación sectorial (por ejemplo, artículo 101.2 de la Ley de Costas de 1988), la autorización judicial. Incluso una habitación en una residencia militar está salvaguardada por ese derecho (STC 189/2004, del 2 noviembre).

La STC del 17 de febrero de 1984 definió el derecho a la inviolabilidad del domicilio como "un auténtico derecho fundamental de la persona, establecido para garantizar el ámbito de privacidad de ésta, dentro del espacio limitado que la propia persona elige y que tiene que caracterizarse precisamente por quedar exento e inmune a las invasiones o agresiones exteriores, de otras personas o de la autoridad pública". ${ }^{24}$

\footnotetext{
${ }^{23}$ Se trataba de una aclaración necesaria, porque la STC del 17 de febrero de 1984 ya requería esa autorización judicial, como luego el artículo 96.3 de la LPAC, pero sin aclarar quién era el juez competente para otorgarla. Por último, el artículo 8.5 de la LJCA (actual artículo 8.6) rescató esa competencia para los juzgados unipersonales de lo contencioso-administrativo, y derogó el artículo 87.2 de la LOPJ.

${ }^{24}$ Como se ha dicho acertadamente, el domicilio inviolable es un espacio en el cual el individuo vive sin estar sujeto necesariamente a los usos y convenciones sociales y ejerce su libertad más íntima. Por ello,
} 
Desde la entrada en vigor de la CE, los titulares del derecho a la inviolabilidad del domicilio fueron, originariamente, sólo las personas físicas (STC del 17 de febrero de 1984, ya vista), si bien luego el TC amplió también a las personas jurídicas esa protección, en su STC 137/1985, recogiendo los postulados constitucionales, legales y jurisprudenciales de los países de nuestro entorno (Alemania, Italia, Austria).

\section{Contenido y garantías del derecho a la inviolabilidad del domicilio}

Titulares del derecho: ya hemos visto la inspirada definición del domicilio como lugar en el que no rigen las convenciones sociales y en el que se produce una emanación de la intimidad y personalidad de la persona, que hay que proteger. Si ello, en relación con las personas físicas supone una protección de todo el domicilio por igual, en las personas jurídicas esa protección es menor, porque sólo afecta a aquellos espacios en los que esa intimidad existe, como puede ocurrir con las sedes sociales o con las habitaciones o espacios donde se encuentren ordenadores, documentos, archivos, etcétera, de la empresa. Lo explicó muy bien la STC 69/1999, del 26 de abril. ${ }^{25}$

Evidentemente, el mandamiento judicial previo autorizando la entrada en el domicilio es el requisito fundamental:

En relación con el control que el juez de lo contencioso-administrativo debe hacer a la hora de conceder o denegar la autorización, el Tribunal Constitucional, en relación con las autorizaciones de entrada, ha declarado que la resolución del órgano jurisdiccional no es más que un eslabón en la cadena o sucesión de actuaciones integrantes del expediente en el que resulta necesaria esa actuación jurisdiccional,

\footnotetext{
a través de este derecho no sólo es objeto de protección el espacio físico en sí mismo considerado, sino lo que en él hay de emanación de la persona y de esfera privada de ella.

25 "Por tanto, cabe entender que el núcleo esencial del domicilio constitucionalmente protegido es el domicilio en cuanto morada de las personas físicas y reducto último de su intimidad personal y familiar. Si bien existen otros ámbitos que gozan de una intensidad menor de protección, como ocurre en el caso de las personas jurídicas, precisamente por faltar esa estrecha vinculación con un ámbito de intimidad en su sentido originario; esto es, el referido a la vida personal y familiar, sólo predicable de las personas físicas. De suerte que, en atención a la naturaleza y la especificidad de los fines de los entes aquí considerados, ha de entenderse que en este ámbito la protección constitucional del domicilio de las personas jurídicas $y$, en lo que aquí importa, de las sociedades mercantiles, sólo se extiende a los espacios físicos que son indispensables para que puedan desarrollar su actividad sin intromisiones ajenas, por constituir el centro de dirección de la sociedad o de un establecimiento dependiente de la misma o servir a la custodia de los documentos u otros soportes de la vida diaria de la sociedad o de su establecimiento que quedan reservados al conocimiento de terceros".
} 
cuya finalidad no es otra que la constatación de que el obligado haya conocido el acto que se pretende ejecutar mediante su formal notificación, y que, asimismo, ha dispuesto del tiempo necesario para su cumplimiento voluntario; sin que ello implique un mero automatismo, pues la intervención del juez autorizante ha de extenderse al control de apariencia sobre la competencia del órgano autor del acto y a la proporcionalidad de la medida adoptada, quedando excluido de dicho control el análisis de los motivos de forma o de fondo que pudieran aducirse para sostener la nulidad o anulabilidad del acto originario, cuya ejecución se pretende materializar por la administración, pues en caso contrario se estaría convirtiendo el procedimiento de autorización en un verdadero proceso revisor de la legalidad de aquel acto originario, con el riesgo de sustraer la legítima competencia del órgano jurisdiccional que debería conocer del recurso contencioso administrativo eventualmente interpuesto contra el mismo.

En la autorización, el juez de lo contencioso-administrativo no se conduce de forma automática, sino que siempre debe realizar una ponderación de los siguientes elementos: ${ }^{26}$

- Existencia de acto administrativo previo, de cobertura de la ejecución forzosa que se pide mediante la entrada en el domicilio, dictado por órgano competente, y fundado en derecho; apariencia de legalidad de dicho acto;

- Procedimiento de ejecución forzosa;

- Eventual afectación a otros derechos o libertades, derivada de la entrada en el domicilio;

- Titular del domicilio;

— Necesidad de dicha entrada para la ejecución forzosa del acto administrativo;

- Adecuación de la entrada a los principios de proporcionalidad: que el tiempo de la visita, que el número de personas que entran en el domicilio y que los objetos susceptibles de registro (en su caso) sean adecuados y limitados para suponer el menoscabo menor posible a la intimidad de la persona o a otros derechos que pudieran ser afectados;

La motivación de la resolución judicial es la principal garantía del procedimiento debe contener brevemente las reflexiones del juez a la hora de valorar los elementos

\footnotetext{
${ }^{26}$ SSTC 137/1985 y 160/1991, 76/1992, 50/1995, del 23 de febrero, 171/1997, del 14 de octubre, 199/1998, del 13 de octubre, 283/2000, del 27 de noviembre y 92/2002, del 22 de abril.
} 
anteriormente citados. En sus SSTC 56/2003, del 24 de marzo y 139/2004, del 13 septiembre, se vuelven a recopilar los elementos dignos de valoración por el juez, declarando que no puede quedar a la discrecionalidad unilateral de la administración el tiempo de su duración y, sobre todo, que la resolución debe ser concreta y personalizada para el caso puntual que se enjuicia, pues una resolución judicial de entrada en domicilio genérica vulneraría el artículo 18, CE, porque podría amparar abusivamente cualquier tipo de entrada. ${ }^{27}$

Cuando haya recaído una sentencia de lo contencioso-administrativo que declara válido el acto administrativo de cobertura (o el acto de trámite de ejecución forzosa), que lleva implícita la necesidad de entrada en el domicilio para su ejecución, la jurisprudencia ha declarado que no se hace precisa la resolución judicial de entrada en domicilio, pues este segundo control judicial sería reduplicativo y no añadiría nada a la protección del derecho (STC 160/1991, del 18 de julio, referente al desalojo de unas viviendas tras una expropiación forzosa declarada válida). Cabría citar también el caso de las declaraciones de ruina, que suelen llevan aparejada la salida del inquilino o propietario de la vivienda. De todas formas, no somos partidarios de estas presunciones jurisprudenciales, porque ningún pronunciamiento judicial sobre el fondo puede prever las circunstancias personales y del caso concreto de la persona que tiene que consentir el desalojo o la entrada en el domicilio: los jueces, por ejemplo, han admitido a veces la permanencia temporal de personas en sus domicilios a pesar de haber sido declarados en ruina técnica, pero no inminente, para proteger su derecho a la vivienda, por tratarse de personas mayores sin residencia ni familia, mientras se les facilitaba una vivienda oficial temporal.

Recurribilidad de la resolución judicial: otra garantía del procedimiento de entrada en domicilio reside en la recurribilidad de la resolución judicial que la permite. Dicha resolución se inserta, como un trámite más, en el procedimiento administrativo de ejecución forzosa, y sería recurrible en apelación ante las salas de lo contenciosoadministrativo de los tribunales superiores de justicia (artículo 81.2, b, LJCA).

\section{BIBLIOGRAFÍA}

\footnotetext{
${ }^{27}$ La motivación tiene un contenido mínimo, que debe expresar con detalle el juicio de proporcionalidad realizado por el juez entre la limitación que se impone al derecho fundamental restringido y su límite, argumentando la idoneidad de las medidas, su necesidad y el debido equilibrio entre el sacrificio sufrido por el derecho fundamental limitado y la ventaja que se obtendrá del mismo; debe precisar también con detalle las circunstancias espaciales y temporales de la entrada y registro, y de ser posible también las personales.
} 
Esta revista forma parte del acervo de la Biblioteca Jurídica Virtual del Instituto de Investigaciones Jurídicas de la UNAM

Álvarez-Cienfuegos SuÁrez, José M., “Ejecución forzosa de los actos de la administración pública y autorización judicial para la entrada en el domicilio", Actualidad Jurídica Aranzadi, núm. 386, 1999.

Ayuso Ruiz-Toledo, "Eficacia de los actos administrativos: suspensión y ejecución", Estudio de la Ley de Régimen Jurídico de las Administraciones públicas y del Procedimiento Administrativo Común, CDJ II, 1994.

BARCELONA LLOP, Javier, Ejecutividad, ejecutoriedad y ejecución forzosa de los actos administrativos, Servicio de Publicaciones de la Universidad de Cantabria, 1995.

Cobo OlverA, Tomás, “La potestad de desahucio administrativo de las entidades Iocales", Actualidad Administrativa, núm. 44, 1992.

Fernández PAStRana, José M., Régimen jurídico y procedimiento de las administraciones públicas. Un estudio de la Ley 30/1.992, 2a. ed., Madrid, Civitas, 1995.

GARCÍA De ENTERRÍA, Eduardo y Fernández RodRÍGUez, Tomás Ramón, Curso de derecho administrativo, 10a. ed., Madrid, Civitas, 2000, t. I.

GARRIDO FAlLA, Fernando, Régimen jurídico y procedimiento de las administraciones públicas. Un estudio de la Ley 30/1.992, 2a. ed., Madrid, Civitas, Madrid, 1995.

González Navarro, Francisco y González Pérez, Jesús, Comentarios a la Ley de Régimen Jurídico de las Administraciones Públicas y Procedimiento Administrativo Común. Ley 30/1.992, del 26 de noviembre, 2a. ed., Madrid, Civitas, 1999, t. II.

GonzÁlez Rivas, Juan José, Comentarios a la Ley 4/1999, del 13 de enero, de modificación de la Ley 30/1992, Madrid, Civitas, 1999.

GonzÁlez SAlinAS, Pedro, "Retorno a la suspensión de la ejecución de la sanción no firme y la necesidad de resolver sobre la petición de suspensión", REDA, núm. 92, 1996.

LAFUENTE BenACHES, “Reflexiones sobre la inviolabilidad del domicilio. A propósito de la STC 160/1991, del 18 de julio", REDA, núm. 73, 1992.

LÓPEZ RAMÓN, F., “Inviolabilidad del domicilio y autotutela administrativa en la jurisprudencia del Tribunal Constitucional", De la jurisprudencia del Tribunal Constitucional, Zaragoza, 1985.

LORENZO DE MEMBIELA, Juan B., "La suspensión de la ejecución del acto administrativo en la Ley Jurisdiccional de 1998", Actualidad Administrativa, núm. 19, 2001. 
Nieto García, Alejandro, "Actos administrativos cuya ejecución precisa de una entrada domiciliaria", RAP, núm. 112, 1997.

PARADA VÁzQUEZ, José Ramón, Régimen jurídico de las administraciones públicas y del procedimiento administrativo común, Madrid, Marcial Pons, 1993.

, Derecho administrativo I. Parte general, 13a. ed., Madrid-Barcelona, Marcial Pons, 2002.

PONT MESTRES, Magín, “Potestad exorbitante de ejecución forzosa de la Administración y el embargo masivo de cuentas corrientes", Revista Técnica Tributaria, núm. 21, 1993.

ReBollo PUIG, "El procedimiento administrativo de ejecución subsidiaria", Revista del Poder Judicial, núm. 57, 2000.

Rodríguez ARANA, Jaime, La suspensión del acto administrativo. En vía de recurso, Madrid, Montecorvo, 1986.

SAINZ MORENO, Fernando, "Sobre la ejecución «en línea directa de continuación del acto» y otros principios de la coacción administrativa", REDA, núm. 13, 1977.

SALA SÁNCHEZ, Pascual (coord.), Comentarios a la reforma del proceso administrativo (análisis de la Ley 4/1999), Valencia, Tirant lo Blanch, 1999.

SANZ LARRUGA, F. J., “La ría administrativa de apremio: una potestad administrativa en expansión", RAP, núm. 117, 1988. 